\title{
Application of L9 Orthogonal Array and Molecular Dynamics Simulation to Design of Metal Film with Strong Adhesion to Resin*
}

\author{
Tomio IWASAKI** \\ **Hitachi Research Laboratory \\ 832-2 Horiguchi, Hitachinaka, Ibaraki, Japan \\ E-mail: tomio.iwasaki.ka@hitachi.com
}

\begin{abstract}
We applied Taguchi experimental design to a nano-structure multilayer film. An L9 orthogonal array and a molecular dynamics simulation were used to design a metal film made up of eight atomic layers so that the metal film was made to have strong adhesion to a resin with a polyphenyl chain (a sequential benzene-ring chain). By carrying out sensitivity analysis with the orthogonal array, among four metal-film factors (the short-side and long-side lattice mismatches with the resin $\Delta a$ and $\Delta b$, surface energy $G$, and cohesive energy $H$ of an atomic-layer laminated metal film), the mismatches were found to be the most dominant factors in the adhesion strength. The author also found that reducing the mismatches and increasing the surface energy and cohesive energy are effective in increasing the adhesion strength and the signal-to-noise ratio. Molecular simulations showed that a copper/ruthenium/cobalt-laminated film is an appropriate structure that has strong adhesion to the resin.
\end{abstract}

Key words: Adhesion Strength, Taguchi Experimental Design, Resin, Thin Film, Interface, Lattice Mismatch, Interconnection

\section{Introduction}

In atomic-scale devices such as future biomechanics devices, semiconductor packages, magnetic recording media, and optical disks, the interface adhesion between thin films made up of different materials has become more and more important. When the interface between different materials is not stable, adhesive fracture occurs at the interface. Therefore, using appropriate materials is one of the keys to preventing adhesive fracture. In semiconductor packages, for example, it is well known that the adhesion of electro-plated nickel-interconnection films to chromium underlayers is very good. However, it is very time-consuming to find such appropriate-material pairs by using an experimental trial-and-error approach. Taguchi experimental design methodology ${ }^{(1)-(3)}$ has been often used to efficiently design macro-scale structures such as propeller fans and diaphragms ${ }^{(1),(2)}$. However, it has been rarely used to design material composition and nano-scale structures. So the author tried applying the Taguchi experimental design methodology to atomic-scale structure of a thin film. 


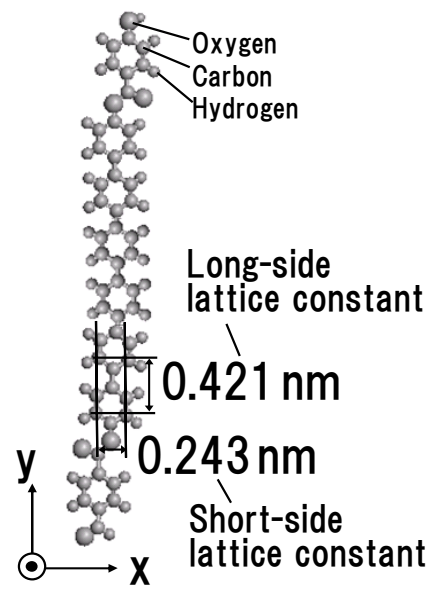

Fig. 1 Resin structure with a polyphenyl chain

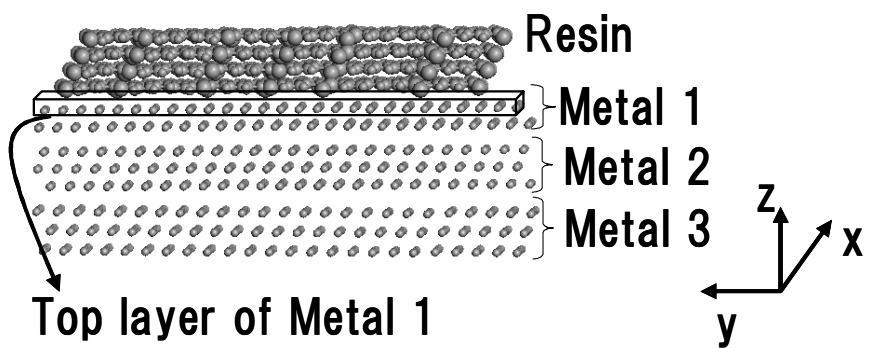

Fig. 2 Resin on atomic-layer laminated metal film

In this study we used Taguchi's method to design an atomic-layer laminated metal film so that the film was made to have strong adhesion to a resin with a polyphenyl chain (a sequential benzene-ring chain), which is often used in semiconductor packages. The adhesion strength of interfaces between the metal film and the resin was evaluated by using molecular-dynamics simulations, which have been found effective in determining the adhesion strength ${ }^{(4)-(9)}$. The purpose of this study is to clarify the dependence of the adhesion strength on four metal-film factors (the short-side and long-side lattice mismatches with the resin $\Delta a$ and $\Delta b$, surface energy $G$, and cohesive energy $H$ of the metal film), and is to find effective methods in strengthening the adhesion.

\section{Analysis Method}

\subsection{Simulation Model and Metal-Film Factors}

The simulation model that we used in this study is an interface between a resin with a polyphenyl chain (Fig. 1) and an atomic-layer laminated metal film, as shown in Fig. 2. Sixteen resin molecules (four layers of molecules), one of which is shown in Fig 1, were used as the resin film. Because by carrying out trial molecular-dynamics simulations, the adhesion strength between the resin and the metal film was found to be almost independent of the total number of metal layers when the number was more than 7 , the number was set at 8 . The metal film is formed by using three metal species, Metal 1 ( 2 atomic layers), Metal 2 (3 atomic layers), and Metal 3 (3 atomic layers), as shown in Fig. 2. The both sizes of the metals in the $x$ and $y$ directions are set at $4.2 \mathrm{~nm}$. The author changed and controlled four factors (the short-side and long-side lattice mismatches with the resin $\Delta a$ and $\Delta b$, surface energy $G$, and cohesive energy $H$ ) of the metal film by changing the three metal species (Metal 1, Metal 2, and Metal 3), and the author investigated how the adhesion strength 


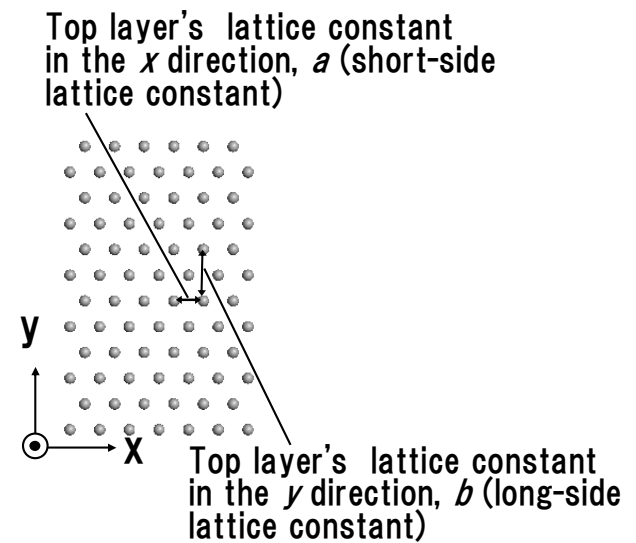

Fig. 3 Centered rectangular lattice of the top layer of Metal 1 and the definition of lattice constants

depends on these factors. Here, the short-side lattice mismatch was defined as the difference between the top layer's short-side lattice constant in the x direction, $a$ (Fig. 3) and the second nearest-neighbor distance $(0.243 \mathrm{~nm})$ between carbon atoms of the benzene ring in the resin (Fig. 1). And the long-side lattice mismatch was defined as the difference between the top layer's long-side lattice constant in the $y$ direction, $b$ (Fig. 3) and the length that is $3^{1 / 2}$ times as long as the second nearest-neighbor distance between carbon atoms of the benzene ring in the resin, that is, $0.421 \mathrm{~nm}$ (Fig. 1). From these definitions the short-side lattice mismatch, $\triangle a$ is calculated as the absolute value of $100(a-0.243) / 0.243$. The long-side lattice mismatch, $\triangle b$ is calculated as the absolute value of $100(b-0.421) / 0.421$. In this study, the $x y$-plane in Fig. 2 is set parallel to the crystal planes of the highest atomic density, which are the (111), (001), and (110) planes for face-centered-cubic (fcc), hexagonal-close-packed (hcp), and body-centered-cubic (bcc) structure metals, respectively. These crystal planes are energetically stable and are experimentally found to be likely to appear at surfaces when metal films are deposited by using physical vapor deposition (PVD).

The surface energy of the metal film, $G$, which is the energy required to generate the metal surface, was defined as half of the difference between the potential energy of the surface-connected state (Fig. 4) and that of the surface-separated state (Fig. 5). The cohesive energy of the metal film was defined as the energy required to break the film into isolated atoms. The surface energy, $G$ and cohesive energy, $H$ were calculated by using the molecular-dynamics software named Forcite of Materials Studio made by Accelrys Co. with a universal force field ${ }^{(10),(11)}$. Described in Refs. (10) and (11), this force field is determined based on the element, its, hybridization, and its connectivity. To clarify the dependence of the adhesion strength on these four factors, we changed and controlled these four factors (the short-side and long-side lattice mismatches with the resin, surface energy, and cohesive
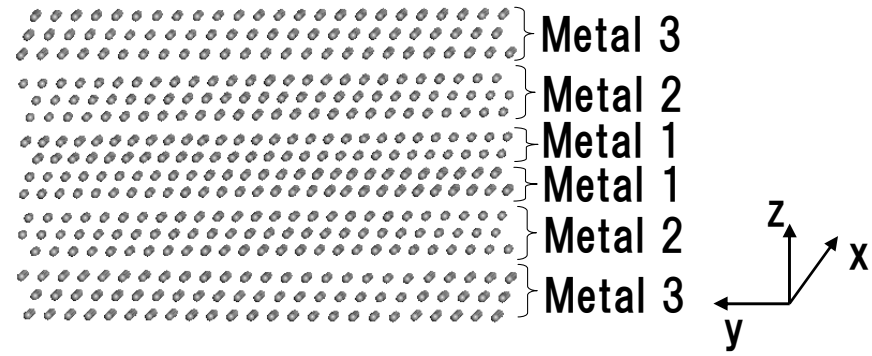

Fig. 4 Surface-connected state of metal film 


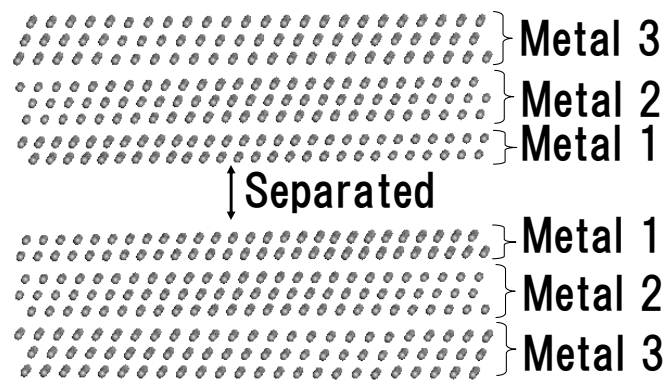

Fig. 5 Surface-separated state of metal film

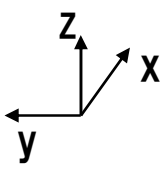

energy) by changing the three metal species, and we tried to find the most appropriate metal set (Metal 1, Metal 2, and Metal 3). The numbers of layers of three metal species Metal 1, Metal 2, and Metal 3 in Fig. 2 were set at 2, 3, and 3, respectively because by carrying out trial molecular-dynamics simulations, these numbers of layers were found to be the most convenient to easily control these four factors. In this study the adhesion strength was evaluated by calculating the adhesive fracture energy ${ }^{(4)-(9)}$ which was defined as the difference between the potential energy of the resin/metal-connected state (Fig. 2) and that of the resin/metal separated state (Fig. 6). This fracture energy was calculated by using the molecular-dynamics software named Forcite (made by Accelrys Co.) with the universal force field ${ }^{(10),(11)}$. In simulations, the temperature was kept at $20{ }^{\circ} \mathrm{C}$ by using the velocity-scaling method.

\subsection{Taguchi Experimental Design Methodology and L9 Orthogonal Array}

When we investigate the dependence of the adhesion strength on the four metal-film factors, we usually change the value of one factor with the other three factors fixed. However, it is time-consuming to find the optimum-parameter set, that is, the most appropriate metal set (Metal 1, Metal 2, and Metal 3) by using this method. So the author used Taguchi experimental design methodology(1)-(3), which is well known effective for efficiently designing the macro-scale structures. In this methodology, an L9 orthogonal array shown in Table 1 is used when there are four control factors, and only nine experiments or simulations are needed to clarify the dependence on the factors ${ }^{(1)}$. Here the

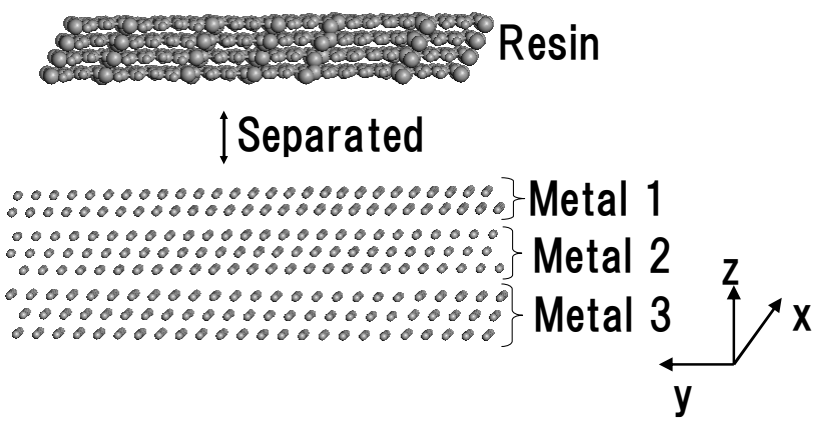

Fig. 6 Resin/metal separated state 
author set level 1, level 2, and level 3 of the four factors at the values shown in Table 2. By changing three metal species (Metal 1, Metal 2, and Metal 3), we obtained 9 metal films that correspond to 9 parameter sets in Table 1. These 9 metal films are shown in Table 3 . By using these 9 metal films, the sensitivity and the signal-to-noise ratio ${ }^{(1)-(3)}$ for the adhesive fracture energy ${ }^{(5)-(7)}$ between the metal film and the resin were calculated. By applying the calculated fracture energy data to Taguchi's method, the sensitivity of Level $\mathrm{j}$ of the i-th factor, $S i j$ is given by ${ }^{(1)-(3)}$

$$
S_{\mathrm{ij}}=10 \log \left[\left(P_{\mathrm{ij}}-Q_{\mathrm{ij}}\right) / \mathrm{n}\right]
$$

where

$$
P_{\mathrm{ij}}=\left(D_{\mathrm{ij} 1}+D_{\mathrm{ij} 2}+\cdots \cdot+D_{\mathrm{ijn}}\right) 2 / \mathrm{n}
$$

and

$$
Q_{\mathrm{ij}}=\left(D_{\mathrm{ij} 1}{ }^{2}+D_{\mathrm{ij} 2}{ }^{2}+\cdots \cdot+D_{\mathrm{ijn}}{ }^{2}-P_{\mathrm{ij}}\right) /(\mathrm{n}-1) .
$$

Here, $D_{\mathrm{ijk}}$ is the k-th datum that belongs to Level $\mathrm{j}$ of the $\mathrm{i}$-th factor, and $\mathrm{n}$ is the number of the data that belong to Level $\mathrm{j}$ of the $\mathrm{i}$-th factor.

The signal-to-noise ratio of Level $\mathrm{j}$ of the $\mathrm{i}$-th factor, $R_{\mathrm{ij}}$ is given by ${ }^{(1)-(3)}$

$$
R_{\mathrm{ij}}=10 \log \left[\left(P_{\mathrm{ij}}-Q_{\mathrm{ij}}\right) /\left(\mathrm{n} Q_{\mathrm{ij}}\right)\right] \text {. }
$$

According to Taguchi's method ${ }^{(1)-(3)}$, the conditions in which $S_{\mathrm{ij}}$ and $R_{\mathrm{ij}}$ are the largest are

Table 1 L9 Orthogonal array

\begin{tabular}{|c|l|l|l|l|}
\hline Condition & $\begin{array}{l}\text { 1st factor: } \\
\text { Short-side } \\
\text { lattice } \\
\text { mismatch } \\
\Delta a\end{array}$ & $\begin{array}{l}\text { 2nd factor: } \\
\text { Long-side } \\
\text { lattice } \\
\text { mismatch } \\
\Delta b\end{array}$ & $\begin{array}{l}\text { 3rd factor: } \\
\text { Surface } \\
\text { energy } \\
G\end{array}$ & $\begin{array}{l}\text { 4th factor: } \\
\text { Cohesive } \\
\text { energy } \\
H\end{array}$ \\
\hline 1 & Level 1 & Level 1 & Level 1 & Level 1 \\
\hline 2 & Level 1 & Level 2 & Level 2 & Level 2 \\
\hline 3 & Level 1 & Level 3 & Level 3 & Level 3 \\
\hline 4 & Level 2 & Level 1 & Level 2 & Level 3 \\
\hline 5 & Level 2 & Level 2 & Level 3 & Level 1 \\
\hline 6 & Level 2 & Level 3 & Level 1 & Level 2 \\
\hline 7 & Level 3 & Level 1 & Level 3 & Level 2 \\
\hline 8 & Level 3 & Level 2 & Level 1 & Level 3 \\
\hline 9 & Level 3 & Level 3 & Level 2 & Level 1 \\
\hline
\end{tabular}

Table 2 Control factors and levels for metal films

\begin{tabular}{|l|l|l|l|l|}
\hline & $\begin{array}{l}\text { 1st factor: } \\
\text { Short-side } \\
\text { lattice } \\
\text { mismatch } \\
\Delta a\end{array}$ & $\begin{array}{l}\text { 2nd factor: } \\
\text { Long-side } \\
\text { lattice } \\
\text { mismatch } \\
\Delta b\end{array}$ & $\begin{array}{l}\text { 3rd } \\
\text { factor: } \\
\text { Surface } \\
\text { energy } \\
G\end{array}$ & $\begin{array}{l}\text { 4th factor: } \\
\text { Cohesive } \\
\text { energy } \\
H\end{array}$ \\
\hline Level 1 & $5 \%$ & $5 \%$ & $1.3 \mathrm{~J} / \mathrm{m}^{2}$ & $3.4 \times 10^{5} \mathrm{~J} / \mathrm{mol}$ \\
\hline Level 2 & $12 \%$ & $12 \%$ & $1.9 \mathrm{~J} / \mathrm{m}^{2}$ & $4.4 \times 10^{5} \mathrm{~J} / \mathrm{mol}$ \\
\hline Level 3 & $19 \%$ & $19 \%$ & $2.5 \mathrm{~J} / \mathrm{m}^{2}$ & $5.4 \times 10^{5} \mathrm{~J} / \mathrm{mol}$ \\
\hline
\end{tabular}


Table 3 Nine metal films corresponding to Table 1 (L9), where Levels 1, 2, and 3 are shown in Table 2

\begin{tabular}{|c|l|l|l|l|}
\hline Metal 1/Metal 2/Metal 3 & $\begin{array}{l}\text { 1st } \\
\text { factor: } \\
\boldsymbol{\Delta a}\end{array}$ & $\begin{array}{l}\text { 2nd } \\
\text { factor: } \\
\boldsymbol{\Delta} b\end{array}$ & $\begin{array}{l}\text { 3rd } \\
\text { factor: } \\
G\end{array}$ & $\begin{array}{l}\text { 4th } \\
\text { factor: } \\
H\end{array}$ \\
\hline $\mathrm{Cu} / \mathrm{Pd} / \mathrm{Rh}$ & Level 1 & Level 1 & Level 1 & Level 1 \\
\hline $\mathrm{Ni} / \mathrm{Pt} / \mathrm{Co}$ & Level 1 & Level 2 & Level 2 & Level 2 \\
\hline $\mathrm{Co} / \mathrm{Au} / \mathrm{Os}$ & Level 1 & Level 3 & Level 3 & Level 3 \\
\hline $\mathrm{Ru} / \mathrm{Co} / \mathrm{Os}$ & Level 2 & Level 1 & Level 2 & Level 3 \\
\hline $\mathrm{Rh} / \mathrm{Pd} / \mathrm{Re}$ & Level 2 & Level 2 & Level 3 & Level 1 \\
\hline $\mathrm{Pd} / \mathrm{Ti} / \mathrm{Pt}$ & Level 2 & Level 3 & Level 1 & Level 2 \\
\hline $\mathrm{Al} / \mathrm{Co} / \mathrm{W}$ & Level 3 & Level 1 & Level 3 & Level 2 \\
\hline $\mathrm{Al} / \mathrm{Pd} / \mathrm{W}$ & Level 3 & Level 2 & Level 1 & Level 3 \\
\hline $\mathrm{Ti} / \mathrm{Al} / \mathrm{Au}$ & Level 3 & Level 3 & Level 2 & Level 1 \\
\hline
\end{tabular}

effective in strengthening the adhesion between the metal film and the resin with the variance of adhesion kept small.

\section{Analysis Results}

The data of adhesive fracture energy $D$ calculated from molecular dynamics is shown in Table 4. Figure 7 shows the sensitivity $S_{\mathrm{ij}}$ calculated by using the fracture energy data (Table 4 ) and Eqs. (1), (2), and (3). Figure 8 shows the signal-to-noise ratio $R_{\mathrm{ij}}$ calculated by using the fracture energy data (Table 4) and Eqs. (2), (3), and (4). From these figures it is found that when the 1st and 2nd factors (the short-side and long-side lattice mismatches) are smallest and when the 3rd and 4th factors (the surface energy and cohesive energy) are largest, the sensitivity and signal-to-noise ratio of the adhesive fracture energy becomes largest. So, reducing the short-side and long-side lattice mismatches and increasing the surface energy and cohesive energy are effective for stabilizing the adhesion. By changing the three metal species (Metal 1, Metal 2, and Metal 3), the author searched for the metal set that satisfies the condition that the 1st and 2nd factors (the short-side and long-side lattice

Table 4 Calculated adhesive fracture energy data corresponding to Table 1 (L9)

\begin{tabular}{|c|l|l|l|l|c|}
\hline $\begin{array}{l}\text { Metal 1/ } \\
\text { Metal 2/ } \\
\text { Metal 3 }\end{array}$ & $\begin{array}{l}\text { 1st } \\
\text { factor: } \\
\Delta a\end{array}$ & $\begin{array}{l}\text { 2nd } \\
\text { factor: } \\
\Delta b\end{array}$ & $\begin{array}{l}\text { 3rd } \\
\text { factor: } \\
G\end{array}$ & $\begin{array}{l}\text { 4th } \\
\text { factor: } \\
H\end{array}$ & $\begin{array}{l}\text { Adhesive } \\
\text { fracture energy } \\
D\left(\mathrm{~J} / \mathrm{m}^{2}\right)\end{array}$ \\
\hline $\mathrm{Cu} / \mathrm{Pd} / \mathrm{Rh}$ & Level 1 & Level 1 & Level 1 & Level 1 & 0.216 \\
\hline $\mathrm{Ni} / \mathrm{Pt} / \mathrm{Co}$ & Level 1 & Level 2 & Level 2 & Level 2 & 0.202 \\
\hline $\mathrm{Co} / \mathrm{Au} / \mathrm{Os}$ & Level 1 & Level 3 & Level 3 & Level 3 & 0.184 \\
\hline $\mathrm{Ru} / \mathrm{Co} / \mathrm{Os}$ & Level 2 & Level 1 & Level 2 & Level 3 & 0.171 \\
\hline $\mathrm{Rh} / \mathrm{Pd} / \mathrm{Re}$ & Level 2 & Level 2 & Level 3 & Level 1 & 0.163 \\
\hline $\mathrm{Pd} / \mathrm{Ti} / \mathrm{Pt}$ & Level 2 & Level 3 & Level 1 & Level 2 & 0.142 \\
\hline $\mathrm{Al} / \mathrm{Co} / \mathrm{W}$ & Level 3 & Level 1 & Level 3 & Level 2 & 0.151 \\
\hline $\mathrm{Al} / \mathrm{Pd} / \mathrm{W}$ & Level 3 & Level 2 & Level 1 & Level 3 & 0.137 \\
\hline $\mathrm{Ti} / \mathrm{Al} / \mathrm{Au}$ & Level 3 & Level 3 & Level 2 & Level 1 & 0.117 \\
\hline
\end{tabular}


mismatches) are small and the 3rd and 4th factors (the surface energy and cohesive energy) are large. And by carrying out 10 trial molecular-dynamics simulations, the author found that the lattice mismatches can be reduced by using $\mathrm{Cu}$, $\mathrm{Co}$, or $\mathrm{Ni}$ as Metal 1 and Metal 3 because lattice constants $\mathrm{a}$ and $\mathrm{b}$ of these metals are close to those of the resin. The author also found that using high-melting-point platinum group ( $\mathrm{Pt}, \mathrm{Ru}, \mathrm{Ir}$, and $\mathrm{Os}$ ) as Metal 2 is effective for increasing the surface energy and cohesive energy. Thus the $\mathrm{Cu} / \mathrm{Ru} / \mathrm{Co}$ film was found to be one example of the best metal sets that satisfy the optimum conditions. Both of the short-side and long-side lattice mismatches of the $\mathrm{Cu} / \mathrm{Ru} / \mathrm{Co}$ film are small $(3.3 \%)$. And the surface energy $\left(2.6 \mathrm{~J} / \mathrm{m}^{2}\right)$ and the cohesive energy $\left(5.5 \times 10^{6} \mathrm{~J} / \mathrm{mol}\right)$ of this film are fairly high. In this case, the adhesive fracture energy is obtained as $0.288 \mathrm{~J} / \mathrm{m}^{2}$, which is higher than those of 9 metal films in Table 4.

To investigate the cause of this strong adhesion, the author calculated the atomic configurations of the interface between the resin and the $\mathrm{Cu} / \mathrm{Ru} / \mathrm{Co}$ film. The atomic configurations calculated from molecular dynamics are shown in Fig. 9. In this figure, the top view of the bottom atomic layer of the resin and the top atomic layer of Metal 1 is shown. Figure 9 shows that copper atoms are located just under the centers of benzene rings (phenyl rings) just like a sunny-side-up structure and that the lattice matching is very well. So the atomic configurations are fairly regular. The regularity caused by the small lattice mismatches is considered to lead to the strong adhesion. On the other hand, the $\mathrm{Co} / \mathrm{Au} / \mathrm{Os}$ film, which is the $3 \mathrm{rd}$ metal set listed in Table 4, has a large lattice mismatch $(\Delta b=19 \%)$ in the $y$ direction. Figure 10 shows the top view of the resin/Co/Au/Os structure. In this figure, cobalt atoms are not located under the centers of benzene rings (phenyl rings) and the sunny-side-up structures do not exist. The relative positions of cobalt atoms

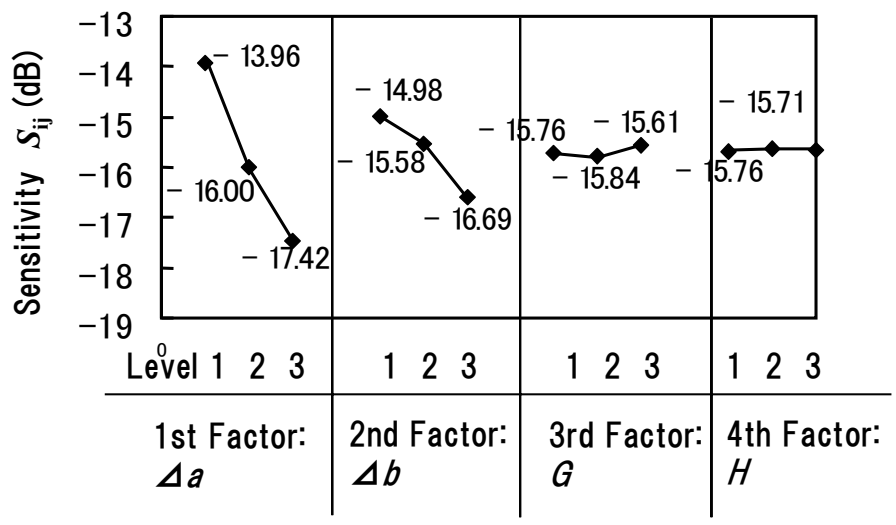

Fig. 7 Results of calculated sensitivity

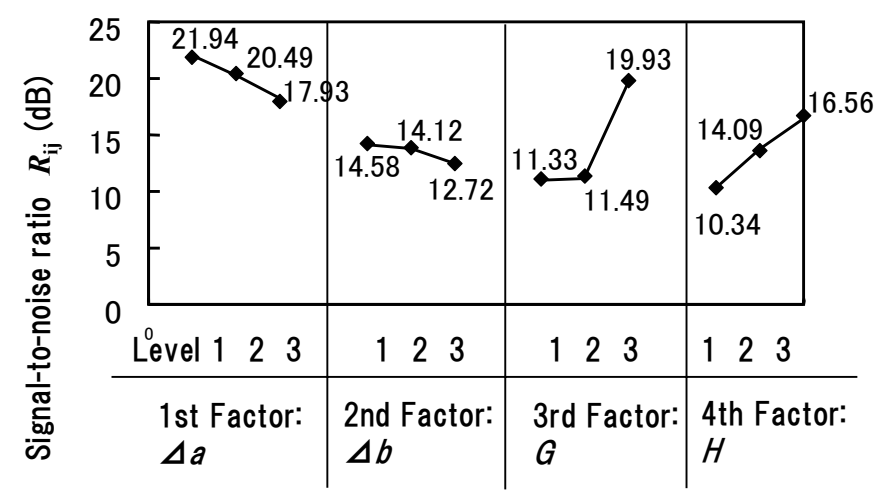

Fig. 8 Results of calculated signal-to-noise ratio 


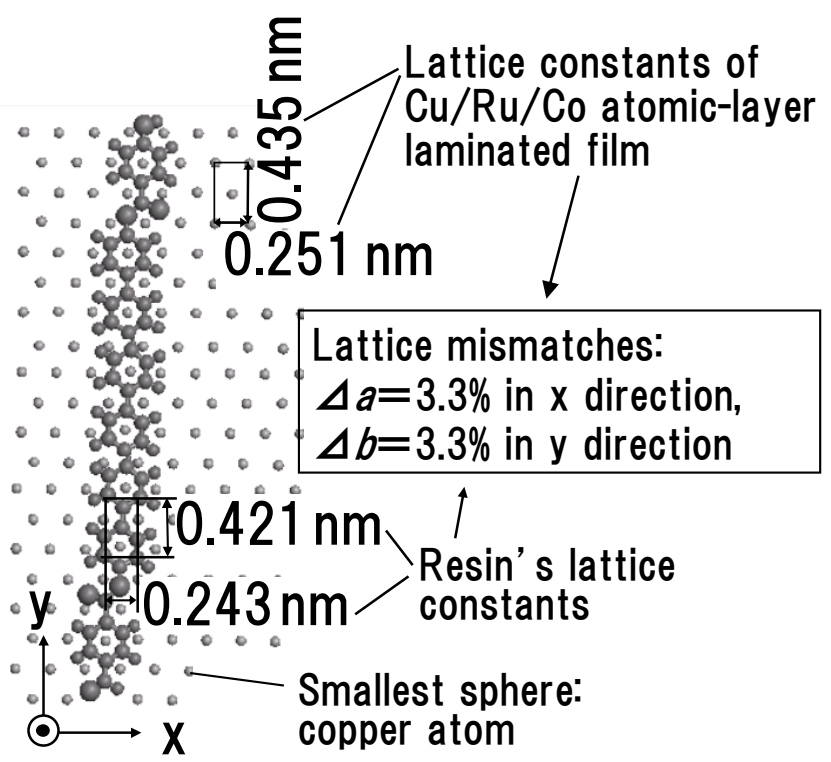

Fig. 9 Top view of the interface between resin and $\mathrm{Cu} / \mathrm{Ru} / \mathrm{Co}$

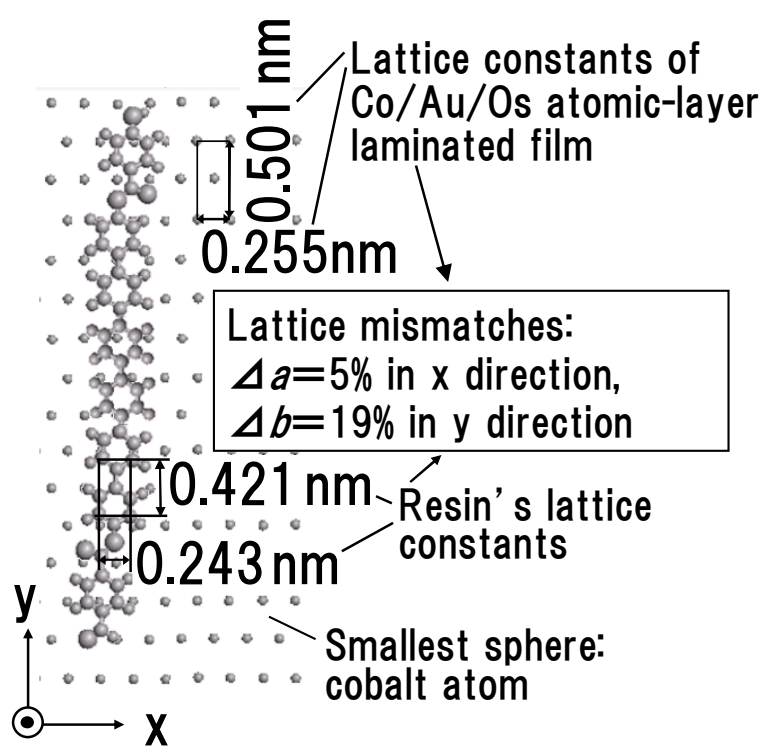

Fig. 10 Top view of the interface between resin and $\mathrm{Co} / \mathrm{Au} / \mathrm{Os}$

against the resin molecule are irregular. Although the $\mathrm{Co} / \mathrm{Au} / \mathrm{Os}$ film has large surface energy and large cohesive energy, this irregularity caused by the large lattice mismatch ( $\triangle b$ $=19 \%)$ is considered to lead to the weaker adhesion $\left(D=0.184 \mathrm{~J} / \mathrm{m}^{2}\right)$ than that of the $\mathrm{Cu} / \mathrm{Ru} / \mathrm{Co}$ film $\left(D=0.288 \mathrm{~J} / \mathrm{m}^{2}\right)$. So the lattice mismatches are considered to be the most dominant factors in the adhesion strength.

In this study, the initial orientation of the resin was set so that the large-side lattice constant is in the $y$ direction. Even when the initial orientation of the resin was set at different orientations, the orientation of the resin was found to finally converge to the same orientation as that in Figs. 9 and 10 in the case of $20^{\circ} \mathrm{C}$ because this orientation makes the system energetically most stable. 


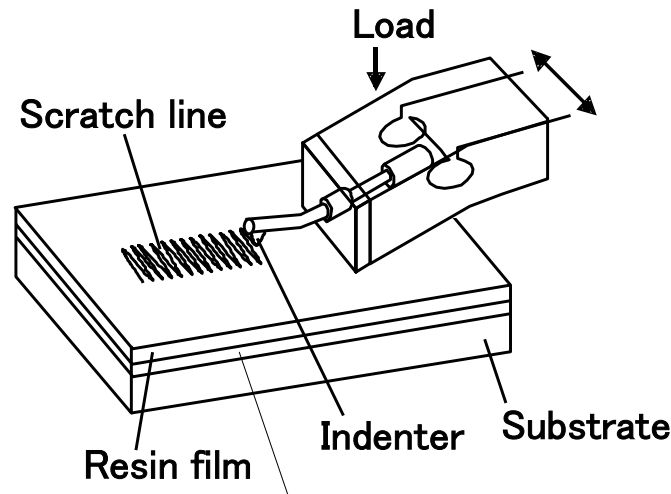

Atomic-layer laminated metal film

Fig. 11 Schematic view of scratch testing

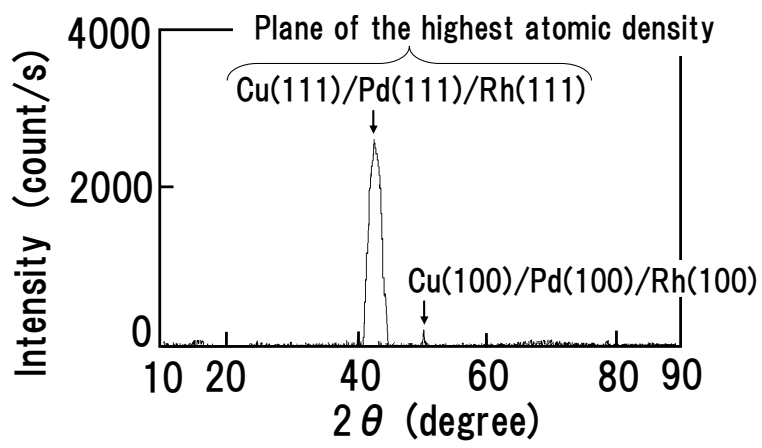

Fig. 12 Result of X-ray diffraction measurements for $\mathrm{Cu}(0.4 \mathrm{~nm}) / \mathrm{Pd}(0.7 \mathrm{~nm}) / \mathrm{Rh}(0.7 \mathrm{~nm})$

\section{Comparison between Simulation and Experiment}

To confirm the effectiveness of the molecular-dynamics simulation technique described in Chapters 2 and 3, the author conducted scratch test on the film-laminated structure (scratch tester: CSR-02 made by Rhesca Co, Ltd) and compared the test results with the simulation results. Recently more advanced methods for measuring adhesion strength have been proposed in a number of research papers ${ }^{(12)-(14)}$. However, these advanced methods were very difficult to apply to fairly strong interfaces such as a polyphenyl-chain-resin/ $\mathrm{Cu}$ interface. Accordingly a simple scratch-testing method that was applicable to the polyphenyl-chain-resin/ $\mathrm{Cu}$ interface was employed. A schematic view of the scratch testing apparatus is shown in Fig. 11. A diamond indenter with a tip radius of $5 \mu \mathrm{m}$ makes the dynamical indentations. During the measurement, load is gradually increased and when it reaches a critical load, adhesive fracture occurs at the interface. The adhesion strength is determined by measuring the critical load $L$ at which the adhesive fracture occurs.

The author used 0.01-mm-thick polyphenyl-chain resin films deposited on atomic-layer-laminated metal films for the scratch test. The molecular structure of the resin films is the same as that in Fig. 1. For the metal films, the author used four laminated films $(\mathrm{Cu} / \mathrm{Pd} / \mathrm{Rh}, \mathrm{Co} / \mathrm{Au} / \mathrm{Os}, \mathrm{Al} / \mathrm{Co} / \mathrm{W}$, and $\mathrm{Ti} / \mathrm{Al} / \mathrm{Au})$ listed in Table 4. These films were deposited on silicon substrates by using physical vapor deposition (PVD). By controlling the deposition time the thicknesses of Metal 1, Metal 2, and Metal 3 were set at the same as those in simulations, that is, 2 atomic layers $(0.4 \mathrm{~nm})$ for Metal 1,3 atomic layers $(0.6 \mathrm{~nm})$ for Metal 2, and 3 atomic layers $(0.6 \mathrm{~nm})$ for Metal 3. The crystal orientation of the metal 


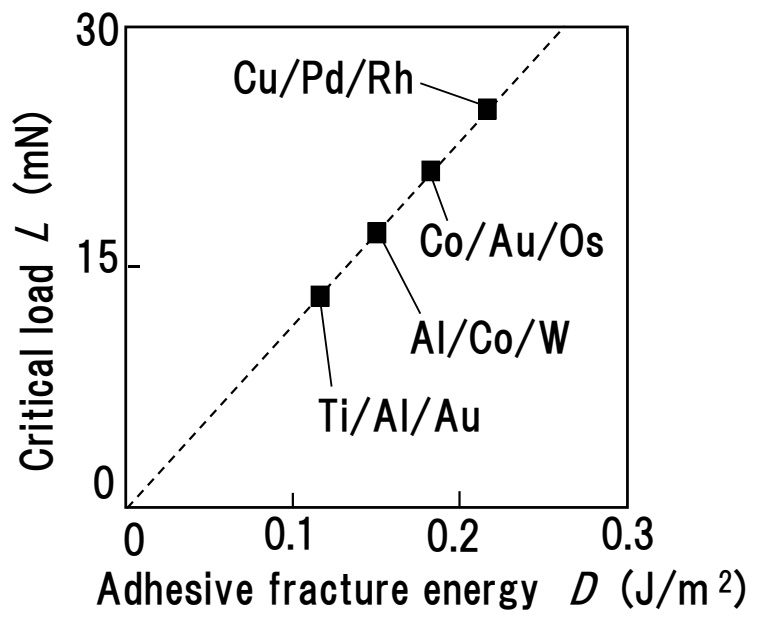

Fig. 13 Adhesive fracture energy calculated from molecular dynamics (MD) and determined critical load measured by scratch testing (experiment)

films was measured by using the $\theta-2 \theta$ scheme of the X-ray diffraction (XRD) analysis. An example of the measured results (for a $\mathrm{Cu} / \mathrm{Pd} / \mathrm{Rh}$ film) is shown in Fig. 12. This figure shows that only the peak for the plane of the highest atomic density was significantly observed. It is considered that because this plane is energetically stable, and because it is more likely to appear at the surface than other crystal planes, other planes were not significantly observed. On the other hand, the orientation of the resin on the metal films was not able to be experimentally measured even by using the X-ray diffraction analysis and transmission electron microscopy (TEM). So we carried out this experiment by assuming that the orientation of the resin was the same as that in the simulations. Because this orientation makes the resin energetically stable, this assumption is thought to be reasonable.

The adhesive fracture energy $D$ obtained from molecular dynamics and the critical load $L$ obtained from scratch test of the interfaces between polyphenyl-chain resin films and laminated metal films $(\mathrm{Cu} / \mathrm{Pd} / \mathrm{Rh}, \mathrm{Co} / \mathrm{Au} / \mathrm{Os}, \mathrm{Al} / \mathrm{Co} / \mathrm{W}$, and $\mathrm{Ti} / \mathrm{Al} / \mathrm{Au})$ are compared in Fig. 13. The ratio of $D_{\mathrm{T} / \mathrm{A} / \mathrm{Au}}, D_{\mathrm{Al} / \mathrm{Co} / \mathrm{W}}, D_{\mathrm{Co} / \mathrm{Au} / \mathrm{Os}}$, and $D_{\mathrm{Cu} / \mathrm{Pd} / \mathrm{Rh}}$, (where $D_{\mathrm{X}}$ denotes the corresponding fracture energies) is $1: 1.29: 1.57: 1.85$. On the other hand, the ratio of $L_{\mathrm{T} / \mathrm{A} / \mathrm{Au}}, L_{\mathrm{A} / \mathrm{C} / \mathrm{W}}, L_{\mathrm{Co} / \mathrm{Au} / \mathrm{Os}}$, and $L_{\mathrm{Cu} / \mathrm{P} / \mathrm{Rh}}$, (where $L_{\mathrm{X}}$ denotes the corresponding critical loads) is $1: 1.30: 1.59: 1.87$. Because these ratios agree well with each other, the adhesion-calculation method is found to be effective for determining the adhesion strength. In this study, to find optimum metal films such as a $\mathrm{Cu} / \mathrm{Ru} / \mathrm{Co}$ film, the author carried out 9 simulations for the L9 orthogonal array and carried out another 10 trial simulations. So the total number was 19. If the Taguchi method with the orthogonal array had not been used, about $27000\left(=30^{3}\right)$ simulations would have been needed because there are about 30 species of metals and because 3 species of metals for Metal 1, Metal 2, and Metal 3 have to been selected. So the Taguchi method is considered to be effective for efficiently selecting appropriate materials for nanotechnology devices.

\section{Discussions}

In this study, the classical molecular-dynamics software named Forcite (made by Accelrys Co.) with the universal force field ${ }^{(10),(11)}$ was used. However, it is very difficult to make sure that the universal force field is effective enough to accurately represent the interatomic interaction at interfaces between the resin and metal films. So the author carried out first principles calculations to obtain physical properties such as adhesive fracture energy, surface energy, and cohesive energy. As a result, it was found that the results obtained from the first principles calculations agreed well with those obtained from the 
classical molecular-dynamics simulations based on the universal force field. This work about the first principles calculations will be published in the near future.

In this paper, the author focused on the four factors (the short-side and long-side lattice mismatches with the resin $\Delta a$ and $\Delta b$, surface energy $G$, and cohesive energy $H$ ). The short-side and long-side lattice mismatches were focused on because geometrical mismatches between metals and resins are considered to be dominant factors in the adhesion strength. On the other hand, the surface energy $G$ and cohesive energy $H$ were focused on because these factors are considered to be related to bond energy between atoms. In bulk metals that have close-packed structures such as face-centered-cubic (fcc) structure and hexagonal close-packed (hcp) structure, the long-side lattice mismatch depends on the short-side lattice mismatch, and the cohesive energy depends on the surface energy. In multilayered nano-scale films, however, those four factors can be independently controlled by selecting appropriate metal species (Metal 1, Metal 2, and Metal 3). This is why an L9 orthogonal array shown in Table can be obtained.

It is difficult to confirm the effectiveness of molecular simulations because the adhesive fracture energy can not be easily measured by experiments. The results of scratch tests include effects of plastic deformation while the adhesive fracture energy calculated from molecular dynamics does not include it. So it is considered that the proportional relationship between the results of molecular dynamics and those of scratch tests shown in Fig. 13 was obtained because the plastic-deformation energy increased in proportion to the increase in the adhesive fracture energy.

\section{Summary}

An L9 orthogonal array and a molecular dynamics simulation were used to design a metal film made up of eight atomic layers so that the metal film was made to have stable adhesion to a polyphenyl-chain resin. By carrying out sensitivity analysis with the orthogonal array the following results were obtained.

(1) Among four factors, the short-side and short-side lattice mismatches with the resin $\Delta a$ and $\Delta b$, surface energy $G$, and cohesive energy $H$ of an atomic-layer laminated metal film, the mismatches were found to be the most dominant factors in the adhesion strength.

(2) Reducing the lattice mismatches and increasing the surface energy and cohesive energy are effective in increasing the adhesion and the signal-to-noise ratio.

(3) A copper/ruthenium/cobalt-laminated film is an appropriate structure that has strong adhesion to the resin.

\section{References}

(1) Suzuki, A., Tominaga, T., Eguchi, T., Kudo, T., and Takada, T., "Study on the fun noise reduction for automotive radiator cooling fans", Mitsubishi Heavy Industries Technical Review, Vol. 43, No. 3, (2006), pp. 23-30.

(2) Imanishi, Y., Baba, T., Hasegawa, T., and Koyano, S., "The optimization of the diaphragm shape based on the quality engineering”, Pioneer $R \& D$, Vol. 12, No. 3, (2003), pp. 39-46.

(3) Taguchi, G., System of Experimental Design, Edited by Don Clausing, New York: UNIPUB/Krous International Publications, Vol. 1 and 2, (1987).

(4) Iwasaki, T., "Molecular dynamics study of adhesion strength and diffusion at interfaces between interconnect materials and underlay materials", Computational Mechanics, Vol.25, No.1, (2000), pp.76-86.

(5) Iwasaki, T., and Miura, T., "Molecular dynamics analysis of adhesion strength of interfaces between thin films", Journal of Materials Research, Vol.16, No.6, (2001), pp. 1789-1794.

(6) Iwasaki, T., "Application of molecular-dynamics simulation to interface stabilization in thin-film devices", International Journal of the Japan Society of Mechanical Engineers, 
Series B, Vol.47, No.3, (2004), pp.470-476.

(7) Iwasaki, T., "Molecular dynamics study of diffusion and atomic configuration in layered structures for Al circuit interconnects”, Computational Mechanics, Vol.24, No.2, (1999), pp.148-154.

(8) Iwasaki, T., "Molecular dynamics study on the effect of lattice mismatch on adhesion strength between organic materials and metals", Journal of the Society of Materials Science, Japan, Vol.58, No.3, (2009), pp.257-261.

(9) Iwasaki, T., "Molecular dynamics study on the effect of lattice mismatch on adhesion strength between ceramics and organic materials", Journal of the Society of Materials Science, Japan, Vol.59, No.2, (2010), pp.165-170.

(10) Rappe, A. K., Casewit, C. J., Colwell, K. S., Goddard III, W. A., and Skiff, W. M., “UFF, a full periodic table force field for molecular mechanics and molecular dynamics simulations, Journal of American Chemical Society, Vol. 114, No.25, (1992), pp.10024-10035.

(11) Casewit, C. J., Colwell, K. S., and Rappe, A. K., "Application of a universal force field to organic molecules, Journal of American Chemical Society, Vol. 114, No.25, (1992), pp.10035-10046.

(12) Kitamura, T., Hirakata, H., and Itsuji, H., "Effect of residual stress on delamination from interface edge between nano-films", Engineering Fracture Mechanics, Vol.70, (2003), pp.2089-2101.

(13) Kitamura, T., Hirakata, H., and Satake, Y., "Applicability of fracture mechanics on brittle delamination of nanoscale film edge", International Journal of the Japan Society of Mechanical Engineers, Series A, Vol.47, No.2, (2004), pp.106-112.

(14) Hirakata, H., Kitamura, T., and Yamamoto, H., "Direct measurement of interface strength between copper submicron-dot and silicon dioxide substrate", International Journal of the Japan Society of Mechanical Engineers, Series A, Vol.47, No.3, (2004), pp.324-330. 